Pre-print de: Balsebre, Armand ; Perona Páez, Juan José ; Fajula, Anna ; Barbeito Veloso, Ma. Luz. The hidden radio audience in Spain: study on children's relationship with the radio. Journal of radio \& audio media, Vol. 18, Num. 2 (2011) , p. 212-230. DOI:10.1080/19376529.2011.615778. Editor de la revista: Broadcast Education Association (BEA) Autors:

- Balsebre, Armand: Professor del Departament de Comunicació Audiovisual i Publicitat II, UAB. ORCID ID: http://orcid.org/0000-0002-0529-586X

- Perona Páez, Juan José: Professor titular del Departament de Comunicació Audiovisual i Publicitat II, UAB. ORCID ID: http://orcid.org/0000-0001-8256-9070

- Fajula, Anna: Professora associada del Departament de Comunicació Audiovisual i Publicitat II, UAB.

- Barbeito Veloso, Ma. Luz: Professora associada del Departament de Comunicació Audiovisual i Publicitat II, UAB. ORCID ID: http://orcid.org/0000-0002-3159-7423

\author{
Journal of Radio and Audio Media
}

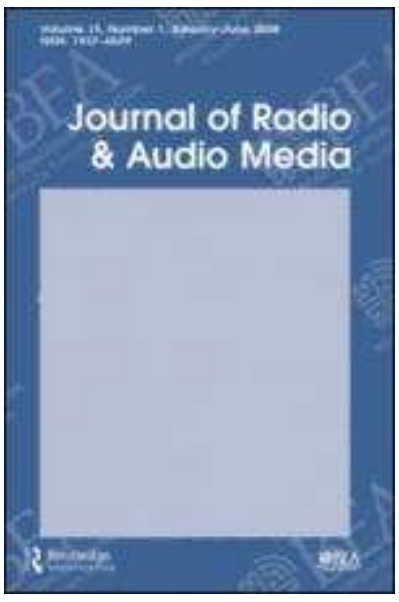

\title{
The Hidden Radio Audience in Spain: Study on Children's Relationship with the Radio
}

\begin{tabular}{|r|l|}
\hline Journal: & Journal of Radio and Audio Media \\
\hline Manuscript ID: & HJRS-2010-0101 \\
\hline Manuscript Type: & Original Article \\
\hline Keywords: & Radio, Children, Audience, EGM, Spain \\
\hline \multicolumn{2}{|l}{} \\
\hline
\end{tabular}

\section{scholarONE" \\ Manuscript Central}




\title{
Title:
}

The Hidden Radio Audience in Spain: Study on Children's Relationship with the Radio

\begin{abstract}
The arbitration imposed in the audience measurement systems used in Spain excludes a major swath of the population as soon as it segments the potential radio audience starting at the age of 14 . Thus, the child-listener is ignored by both the programming and advertising strategies. However, is this marginalisation fair? The purpose of this article is to answer this and other questions and to demonstrate to what extent the existence of the child-listener is a sufficient condition to seek mechanisms that enable children to be included in radio audience measurement systems.
\end{abstract}

\author{
KEY WORDS \\ Radio, children, audience, EGM, Spain
}

\section{Introduction}

The General Media Studies (Estudio General de Medios, or EGM) survey is the measuring system that has been used in Spain since October 1968 to periodically sketch the generic audience and profile of radio listeners (Blanch, 1993). The EGM reveals the number of listeners for each station, so its results play a key role in determining the programming policies of the main operators. Yet it is also extremely important for planning the advertising investment and fees of Spanish commercial radio broadcasting. The entity in charge of conducting the EGM is the Association for Media Investigation (Asociación para la Investigación de Medios de Comunicación, or AIMC), which 
analyses consumption in radio and other media. The EGM is an annual study that is divided into three different tiers; that is, the sample is divided into three parts that are equal in size and composition. The universe, as the AIMC itself defines it, is made up of individuals aged 14 and above who live in single-family households in peninsular Spain, the Balearic Islands and the Canary Islands.

The annual sample that the EGM works with is made up of 30,000 individuals who are administered a multimedia survey using the methodology of face-to-face interviews with a structured, almost entirely close-ended questionnaire at the interviewee's home. In the study of the radio audience, the sample is expanded to 37,000 telephone interviews all around Spain, and 12,400 further telephone interviews for the autonomous community of Catalonia. ${ }^{1}$ The radio EGM thus encompasses the results of the 79,400 surveys conducted each year. The interviewees provide information on their consumption (stations and programmes that they listen to, for how long, where they listen, etc.), always based on their "recollection of yesterday". The information they provide is compiled by the surveyors through the CAPI (Computer Assisted Personal Interviewing) technique, and the figures are later tabulated. The companies in charge of conducting the field work (TNS Market Research, Random and Synovate) are the ones that supervise the interviews, although 10\% of them are also directly supervised by AIMC itself.

Given its importance, the EGL gained status as the indisputable arbiter of Spanish radio audiences. Just like in other countries, the main star-announcers of Spanish radio today wage veritable battles to attract listeners to their station, especially during prime-time (between 9 and $11 \mathrm{am}$ ), by offering the same contents at the same times. In Spain, for several decades now this dynamic has led to highly homogenous, conventional programming characterised by the presence of large blocs which feature little more than three basic options: news, entertainment (meaning morning and evening magazines) and sports. "The scene of inertia that characterises the structural model of Spanish radio today, primarily the general radio stations which manage the highest advertising investment and define the institutional image of the medium, ultimately works as a mirror for the advertising 


\section{Objectives, material and methods of the study}

The arbitration imposed by the measurement system used by the EGM not only plays the role described above but also excludes a major swath of the population as soon as it segments potential radio audiences starting at the age of $14 .^{2}$ In this way, always according to the EGM, a radio listener can only be an individual aged 14 or above, meaning that since they are omitted from the EGM surveys, the child-listeners of today are also ignored by advertising strategists and programmers. This situation is also repeated in other countries. Although it is true that there are some studies on children's radio habits and use, ${ }^{3}$ the prevailing tone seems to be the same as in Spain: children are ignored as an audience, although this does not mean that they do not form part of the audience. "I never subscribed to the philosophy of most radio people, which is: kids don't listen radio" (in Petrozzello, D., 1996, p. 66). ${ }^{4}$ With regard to advertisers' passive, avoidance-based attitude toward this target, the underlying problem seems to be, as pointed out, the lack of measurement instruments which would enable us to quantify and qualify this audience: "Many advertisers consistently have shied away from children's radio because there is no formal measurement service tallying the size of the audience" (Petrozzello, D., 1996, p. 66).

The second baby boom in Spanish society, triggered by the rise in the migratory flows to the large cities and policies that foster family regroupings, as well as certain actions conducted to promote the birth rate, have quantitatively boosted the importance of the age bracket between the ages of 0 and 14, a bracket that will soon account for around $20 \%$ of the population of Spain. When 
calculating and studying the potential radio audience in Spain, the EGM survey therefore marginalises one out of every five Spaniards. But is this marginalisation fair? Do children under the age of 14 in fact not listen to the radio, and therefore should they not be tallied by the main system used to measure radio audiences? Might the exclusion of the child population from the universe of radio communication influence the future survival of the medium?

The purpose of this article, which falls within the prime avenues of research of the Publiradio ${ }^{6}$ group on research and teaching innovation, affiliated with the Department of Audiovisual Communication and Advertising II of the Autonomous University of Barcelona, consists precisely of answering these questions and demonstrating to what extent the existence of the child-listener is a sufficient condition for seeking new audience measurement instruments that would allow the child population to be included. In this sense, this study reveals new information on children's relationship with the radio in Spain. Regardless of the case discussed above on the Peruvian market, we can find similar initiatives conducted in Minnesota (Davis, 1994) and India (Jayaprakash, 2000), even though they are among the few attempts to examine this issue. The majority of studies related to children and the mass media have focused on visual media (Burton, 2008), and when they have examined the radio scene, they have done so predominantly from the perspective of educational radio, both abroad (Cantril and Allport, 1935; Spain, 1977; Jamison, 1978; Fryer, 1991; Morton, 2008; Burton, 2008) and in Spain (González, 1989; Gascón, 1991; Muñoz, 1994; Merayo, 2000; González, 2003).

In order to achieve the aforementioned objective, a field study ${ }^{7}$ was conducted with a sample of 212 children attending five schools in Barcelona (Spain), four of them located inside the city and one of them in the greater metropolitan area. During academic year 2006-07 (when this study was performed), 120 of these 212 children were in fourth grade (8-9 years old), while 92 were in sixth grade (12-13 years old). By schools and age brackets, the breakdown of the sample was as follows: 


\section{INSERT TABLE 1}

Given the nature of the sample, in order to conduct the study we rejected the possibility of using an information-gathering instrument (such as a questionnaire with a series of questions) and instead chose to assign each of the experimental subjects to write an essay entitled What the Radio Means to Me. Essays are an assignment which the children are familiar, and it was therefore decided that the arguments captured on paper might be quite valuable for achieving the objectives. In order to process the information from such an open instrument as an essay, once they were revised and the main common denominators were extracted, we designed a matrix in which information could be extracted into the following categories:

- Definition of radio

- Use of the radio

- Contents listened to on the radio

- Radio listening habits (where, when and with whom)

- Stations and announcers listened to

- Assessment of radio

- Other relevant comments

It should be noted that in order to write the essay on the generic subject What the Radio Means to $M e$, the children writing the compositions were given no further instructions. For this reason, not all the experimental subjects talked about the same topics, nor did they discuss all the categories mentioned above.

The dynamic used to gather and tabulate the information was as follows: once the essays were written, the research team collected, read and analysed them, extracting the main topics discussed in 
each of them. Based on these items, the categories covering the generic themes under which the information could be covered were drawn up. The list above is the outcome of this analysis and covers the basic topics mentioned in the majority of the essays. Formally, each essay was codified with a two-digit number: the grade (4 or 6 depending on whether the student was in fourth or sixth grade) and the student number (assigned randomly according to the order in which the essays were handed in), followed by the name of the school. This nomenclature can be seen in the quotations that appear throughout this article. Statistically, the number of students that mentioned the each of the subjects at least once was as follows:

- Definition of radio: 212 subjects (100\% of the sample)

- Use of the radio: 52 subjects $(24.5 \%)$

- Contents listened to on the radio: 94 subjects (44.3\%)

- Radio listening habits (where, when and with whom): 111 subjects (52.4\%)

- Stations and announcers listened to: 85 subjects (40.1\%)

- Assessment of radio: 75 subjects $(35.4 \%)$

- Other relevant comments. A total of 111 comments were made about topics like the radio and parents, radio at school, or programmes and contents that the students like listening to. In this case, the data is not expressed in percentages, as the same child may offer more than one comment (they can talk about radio at their home, the programmes they like listening to and more).

\section{INSERT GRAPH 1}

\section{Results and discussion}




\section{Overall knowledge of the medium: The radio according to children}

The analysis of the results obtained from processing the essays highlights the fact that, regardless of their age, all the children in the sample were familiar with the radio. The terms they used to refer to it included device, medium, invention, channel, object, machine, place, box, broadcaster/station/programme, announcer and room/place. A significant number of the children (25\%) defined it as "a device for listening to music and the news", and $12 \%$ as "a medium through which we hear about what's happening and listen to music". 8

Likewise, differences can be seen in the language used in the definitions offered by fourth and sixth graders. Thus, while the younger students resort to simpler concepts like "it's a device" or "it's a room with people talking and microphones", and they relate it to music, news and sports, the sixth graders talk more about a "medium" and using terms like broadcasters, stations and programmes.

Overall, the number of concepts that the children relate to radio is surprising. If a priori the level of knowledge of the medium seemed low and limited, once the analysis of the essays was over we saw how the children used a vast number of words about the radio, more than 20 in total. A visual representation of the most representative terms ${ }^{9}$ that were named in the 212 essays on radio yields the following illustration:

\section{INSERT GRAPH 2}

The children in the sample also displayed a high degree of knowledge about the radio spectrum. Some of them included approximations, citations or references to broadcasters in their definitions, such as "I know very little about the radio, but I know that the programme Catalunya Ràdio is made on Diagonal Avenue" (Student 4.13 Montserdà-Santapau: fourth grade); "I listen to Flaixback on the radio" (Student 4.3 Escola del Mar: fourth grade); "Radio has a lot of channels. In Catalonia 
there are 80 radio stations. I don't know how many there are in the world, but there are a lot like 40 Principales or M80 Radio" (Student 4.4 Escola del Mar: fourth grade); and "In the whole world there are around 8,000 radio stations" (Student 4.17 Escola del Mar: fourth grade).

Even though the arguments used are clearly childlike (they cite figures as if they were absolute truths), the interesting part is that regardless of the numbers they cite, the experimental subjects are aware of the existence of a wide variety of broadcasters. More than half of them cite the name of at least one station. Thus, the radio station that the children in the sample are the most familiar with is Cadena 40 Principales, followed by Catalunya Ràdio, M80 Radio, RAC 105 and Europa FM. With the exception of Catalunya Ràdio, a public network owned by the Corporació Catalana de Mitjans Audiovisuals (CCMA), which offers general programming, the other broadcasters base their contents on exploiting a musical format. What particularly drew our attention was the fact that all told, up to 26 different radio stations were mentioned, which shows the children's high degree of knowledge of the Catalan and Spanish radio universe.

With regard to their use of the radio, there are three main themes in most of the responses: music, football and the news. Those whose essays talk about what they used the radio for $(24.5 \%$ of the total sample) mainly mentioned that they used it to listen to music, football matches (they particularly stated that they listened to the matches when they cannot see them on the TV) and the news. More marginally, there are also mentions of using the radio to listen to weather or traffic reports. ${ }^{10}$

INSERT TABLE 2

\section{Listening habits among the child audience}

Almost $61 \%$ of the experimental subjects claimed that they listened to the radio regularly, although the majority of children declared that they do so in the company of their father, mother or both 
parents, or other family members (grandparents, siblings). In fact, only two girls said that they listened to the radio without anyone else around. Furthermore, practically $100 \%$ of the child audience in the sample cited the radio as a device through which they tune into the different stations. Only one person mentioned that they listened to the radio via computer, and three more mentioned an MP3 player. This reality contrasts with the popular belief that children do not listen to radio, and likewise it also contradicts statements like: “(...) the radio is a medium that has been slow to capture the child audience, which does not feel attracted to it until adolescence" (González Conde, J., 2003, p. 2).

One of the main times when children listen to the radio is when they are travelling by car to school or from school. This is a time when children consume the programming on the station that their fellow riders have tuned into on the radio, as some children state that the car is the only place they have contact with the radio: "At home we don't listen much, but we do listen a lot in the car" (Student 6.13 Montserdà-Santapau: sixth grade). With regard to consumption at home, some children mention home generically. Those who delve into further detail mention their bedroom or one of their sibling's bedrooms, the kitchen, the dining room and the bathroom as the places where they often listen to the radio.

The rooms at home are also correlated with performing specific activities as they consume radio programmes and channels. Thus, listening to the radio in the bedroom comes hand in hand with doing homework, going to bed or getting up; in the kitchen with breakfast or when their mother is cooking; and in the bathroom with getting ready to go out, or especially with the daily shower or bath. We should recall that the presence of radios in children's rooms was particularly significant in the late 1990s as well, given that according to the results of a qualitative study on the use, consumption and attitudes of Spanish children and young adults towards the different media and electronic devices (Garitaonandia, Juaristi and Oleada, 1999), the most important devices in children's and young adults' rooms were ones that played music (radio 63\%, Walkman 61\% and stereo $38 \%)$. 
The broadcast of sports programmes, especially broadcasts of football matches on weekend afternoons and evenings, are also a major time when children listen to the radio; $12.74 \%$ of the sample claimed to listen to broadcasts of football games on the radio, although almost all of them state that they do it when they cannot see the match on the television: "[listening to the radio] at the home of friends who don't have Canal+" (Student 6.9 Escola del Mar: sixth grade); "When I can't go to a match and they don't show it on the TV I listen to it on the radio" (Student 6.27 MontserdàSantapau: sixth grade). From these comments we can deduce that when the children talk about football matches they are referring to matches regarded as "high interest". Practically $100 \%$ of those who mentioned football added the specificity of the Football Club Barcelona. We can assume that in this case, the geographical setting clearly affects the fact that these children express a preference for this sports team. There are also cases in which the students mention that they see the match on the television (usually with their father) as they listen to the broadcast of the same match on the radio (volume turned down on the television): "My father turns on the radio when Barça is playing a match and when he turns it on he lowers the volume on the TV at the same time" (Student 4.18 Jacint Verdaguer: fourth grade).

\section{Favourite programmes}

The kind of stations cited by the children clearly reveals that music is the content preferred by the vast majority of the sample, so much so that 48 subjects ( $23 \%$ of the total) explicitly mention it. Football matches come in second place, mentioned by 27 children (12.7\%), while the news is only mentioned by 15 children. $^{11}$ Other contents mentioned include sports and the weather, although there are also a few mentions of advertisements, contests and "joke programmes".

Generally speaking, we can see a trend to associate content with a given station (such as music on Los 40 Principales and music on Flaix FM, etc.). However, very few times (seven in total) do 
children specify what they listen to when they cite a specific station. With regard to their preferences, that is, what they like to listen to on the radio, they mention a wide range of ideas, including jokes, riddles and TV cartoons. Their favourite format by far is the contest in which listeners can win prizes by phoning the station. They also mention that they would like to listen to more things for young people, more music by their favourite bands and singers and broadcast children's programmes targeted at their age group. To a lesser extent, they mention films for the radio, animal contests, nature sounds, videogame programmes and school matches at their schools (local radio). Thus, from a generic standpoint, the results on the perception of the medium by a child audience dovetail with the research conducted in southern India, where the children regarded radio as a private medium that kept them company and related it to fun and information (Jayaprakash, 2000).

\section{Children's assessment of the radio}

The children have a positive view of radio in general. Even though not all the subjects in the sample expressed their like or dislike of it, most of those who did ( 75 subjects, $35.4 \%$ of the total) stated that they liked it. Of this 75,48 children (64\%) stated that they like the radio: "Both my father and I like listening to the radio a lot" (Student 6.36 Montserdà-Santapau: sixth grade); "I like it - you can listen to interesting things on it" (Student 4.4 Escola del Mar: fourth grade); "Radio is great because it has great songs and they talk about interesting things like football matches" (Student 4.8 Escola del Mar: fourth grade); "Radio is a great device. I have fun with the radio because I can listen to rock music and everything" (Student 4.14 Escola del Mar: fourth grade); and "I would die if my radio broke down because radio is like life itself" (Student 6.10 Drassanes: sixth grade). These arguments clearly show the interest that these children have in the radio. The remaining $36 \%$ (27 subjects) is made up of the children who stated that they do not like the radio. 


\section{INSERT GRAPH 3}

Within the category of "I don't like the radio" we can distinguish two sub-groups: the largest one (18 out of $27 ; 66.7 \%$ ) states that they do not like the radio; they simply compare it to the television and conclude that they prefer to the television over the radio. The absence of pictures is the factor cited most often as the radio's main weakness, and it is the clearest factor leading them to prefer the television: "I prefer the TV, but that doesn't mean that I don't like the radio" (Student 6.3 Escola del Mar: sixth grade); “I don’t like it because there are no pictures” (Student 4.12 Jacint Verdaguer: fourth grade); and "I like the TV much better than the radio because you can see the pictures on the TV and so I get a better idea of what's going on in the world" (Student 6.27 Montserdà-Santa Pau: sixth grade). Therefore, we find that a large swath of the subjects who choose the option "I don't like the radio" actually say this thinking about what they prefer: it is not that they do not like the radio as much as that they do not like it as much as the television. Those who categorically state that they do not like the radio make up a much smaller percentage ( 9 out of $27 ; 33.3 \%$ ).

Bearing this point in mind, the children's overall assessment of the radio can be summarised by the following graph:

\section{INSERT GRAPH 4}

With regard to the radio's degree of affinity with the young audience, from the essays we see that the majority of children do not feel that the radio is particularly designed with them in mind as the 
target audience. The essays written by a total of 26 subjects mentioned whom they think the radio target is. The majority (48\%) says that they think the radio is targeted to "everyone", followed by those who think that the radio is a medium for adults $(12 \%)$ and for the elderly $(8 \%)$. The remaining references are merely anecdotal, as the children make comments like: "celebrities use it to hear what the critics say"; "politicians and celebrities listen to it"; "people interested in learning what's happening in the world"; "people who want to find out things before other people"; and "people who like music"; "people who are alone and blind people...".

Even though these comments are primarily anecdotal, as mentioned above, it is also true that we can glean extremely valuable information from them. Indirectly, the children are talking about the characteristics of the radio: when they say that people who want to find out things before anyone else listen to the radio, they are talking about its immediacy; when they mention blind people as a radio target audience, they are referring to its capacity for suggestion and its ability to stimulate the imagination; when they mention that it is used by people who live alone, they are referring to it as a medium that keeps people company; ${ }^{12}$ and when they say that people interested in finding out what is happening in the world listen to the radio, they are talking about its specific nature as a means of disseminating information. But none of them identify with the radio; none of them feels that the radio speaks to them in particular: "I think that older people [meaning adults] listen to the radio more because there are no programmes for children" (Student 6.37 Montserdà-Santa Pau: sixth grade); "I'd get rid of so much news on the radio and put on more things for young people" (Student 6.8 Escola del Mar: sixth grade). Generally speaking, the young audience does not see itself reflected in the radio programmes; they are aware that the medium does not target children, that it excludes them as a target audience, and this exclusion both directly and indirectly influences their closeness to the radio. We precisely believe that their inclusion as an audience could end up raising children's opinion of the radio: "Kids listen to radio if radio reaches out to them. If you provide a product, kids will listen to it" (Petrozzello,D., 1996, p. 66), and likewise, this could also contribute to nurturing future radio listeners. 


\section{Conclusions}

The results of this study reveal the existence of a swath of the population (children under the age of 14) who is quite familiar with Catalan and Spanish radio and who also claims to listen to it, in relatively high absolute numbers, over some station. This circumstance, which questions the arbitration imposed by the General Media Studies (in that it does not consider anyone under the aforementioned age threshold a radio listener), is a sufficient condition for seeking new instruments to measure audiences that would include children, a hidden age bracket that is very important and strategically decisive for the future survival of the radio in Spain. The child audience exists, but it is ignored by radio programmers and planners.

Measuring the child radio audience could encourage the launch of programmes designed specifically for them, with the consequent diversification of an extraordinarily homogenous range of programmes on both publically owned networks and private operators. Likewise, it might also encourage Internet stations targeted at children to be started, as has taken place in France, which has a range of programmes that includes three famous stations (Superloustic, Radio Junior and Radio Bébés)), and Argentina, with the project Radiokids (http://www.radiokids.com.ar). It could also promote educational media actions that have been conducted in Spain with the support of the public administrations (Perona, 2009), such as the Xtec Ràdio experiment and the Media Radio application from the now-defunct National Centre of Educational Information and Communication (CNICE), now ISFTIC.

In the field of advertising, knowledge of the programmes that children listen to, as well as their main consumption habits, could foster the development of specific campaigns of all kinds (commercial, institutional and/or social) aimed at fostering subjects like education in values and prevention. Advertisers are ignoring children as an audience because theoretically they do not exist 
as such. However, in reality, children are not only familiar with radio advertising, in some cases they also mention it and prefer it: "What I like the most about the radio is listening to the ads and football matches" (Student 4.14 Escola del Mar: fourth grade); "[the radio] is a medium that can be used for many purposes, such as listening to music, tarot cards, advertising, etc." (Student 6.12 Jacint Verdager: sixth grade). There is no doubt that including children as a radio audience would contribute to also changing the radio advertising scene (new kinds of products within the batteries of ads, new advertisement sectors, the possibility of experimenting with new advertising formats, etc.).

Nor should we forget institutional advertising. The child segment is a particularly important audience for the target market of this kind of advertising promoted by the advertising State for a number of reasons, first and foremost because in the future they will become the adult population. As a result, it is particularly important to lay solid foundations in terms of values, attitudes and socially-responsible behaviours. Therefore, it is crucial for institutional advertising campaigns on issues like the use of active and passive security devices in cars, anti-smoking, anti-drugs, harmonious societal coexistence and acceptance of differences to have a proper impact on children. Secondly, prevention campaigns are basic in that they help to create both individual awareness (what I think) and collective awareness (what the group thinks; if the majority thinks/acts in one way it is easy for the individual who thinks/acts differently to give up their way of thinking/acting and adopt the prevailing way of thinking/behaving; especially when these beliefs/behaviours are the ones promoted by those who occupy hierarchically dominant positions among this group in terms of their social role).

\section{Notes}

${ }^{1}$ AIMC figures, 2009 EGM sample. 
${ }^{2}$ This huge gap within the EGM was most likely what drove the AIMC itself to launch the Study on the Child/Teen Audience in Media in Spain (Estudio de audiencia infantil/juvenil de medios en España), which was designed to study the relationships between young people aged eight to thirteen and the media. The method used is also the personal interview, and the sample includes 3,992 interviews. Four editions of this study have been conducted, in 1998, 2002, 2004 and 2008. However, the tool used in radio advertising planning is still the EGM.

${ }^{3}$ The Study on Children's Consumption of Television and Radio (Estudio sobre consumo televisivo y radial infantil, 2007) contains a comprehensive analysis of radio consumption by children aged seven to fourteen. This study, which examines the market in Peru, is one of a handful of examples available on children's relationship to the radio. Available at http://www.concortv.net.

${ }^{4}$ Quotation from Cristopher Dal, President of CBC, in Petrozzello, D. (1996) “Children's radio: a format whose time has come" in Broadcasting \& Cable, Vol. 126, no. 42, p. 66.

${ }^{5}$ According to the National Statistical Institute (INE), in 2009 there will be 1,369 births per day, meaning that the birth rate will reach its highest point since 1983.

${ }^{6}$ In addition to the authors of this article, Publiradio is a group made up of UAB professors José María Ricarte, Margarida Blanch and Ana María Enrique. Publiradio was created with the goals of shedding light on the communicative possibilities of the radio in the realm of advertising, and more particularly of suggesting new creative resources. The group has an educational website, www.publiradio.net. In 2009, Publiradio earned recognition as an emerging research group from the regional government of Catalonia (Generalitat de Catalunya, SGR2009-0454), with the name of the Research Group in Radio Advertising and Communication (Grup de Recerca en Publicitat $i$ Comunicació Radiofònica).

${ }^{7}$ As part of a more sweeping study on The Radio as a Means of Social Integration: Development of an Instrument to Measure Excluded Audiences for Holding Institutional Campaigns of Social Interest (La radio como medio de integración social: desarrollo de un instrumento de medición de audiencias excluidas para la realización de campañas institucionales de interés social), financed 
by the Ministry of Education and Science from 2005 to 2008 (SEJ2005-07853). In 2009, the Spanish Ministry of Science and Technology granted the research group the project entitled The Digital Sono-sphere as a New Environment for Receiving Sound Messages among Young Adults: A Study of Habits to Develop New Formats of Institutional Advertising (La sono-esfera digital como nuevo entorno de recepción de mensajes sonoros entre los jóvenes. Estudio de los hábitos para el desarrollo de nuevos formatos de publicidad institucional, SOC2009-12236), about which this article mentions several perspectives.

${ }^{8}$ Practically all the children who defined the radio as a device or a kind of medium then went on to relate it to music and the news. The conceptualisation we offer in quotation marks is a standard definition and does not imply that the entire sample defined it the same way.

${ }^{9}$ The less frequently mentioned terms, like buttons, volume, earphones, loudspeakers, square or car, were not included in the word map.

${ }^{10}$ We believe that in these cases, the children are not listening on their own initiative, rather they access the broadcast contents through other people (their parents, grandparents, etc.), particularly when they are in the car on their way to and from home and school.

${ }^{11}$ The figures differ from those shown in Table 3, as the former compiles the results in which the subject referred explicitly to "I use the radio for this". Here, any mention of the genres that appear throughout the essays is included.

12 The radio manages to be closer to the consumer. The relationship that this medium forges with the listener is tinged with an intimacy that is not found in other media. Plus, the radio audience for a given broadcaster or station creates ties that display a high degree of loyalty (Barbeito and Fajula, 2005).

\section{References}


Balsebre, A. et al. (2006). Los mitos de la publicidad radiofónica. Estrategias de la comunicación publicitaria en la radio española. Madrid: Cátedra.

Barbeito, M.L. y Fajula, A. (2005). La radio publicitaria: el peso del inmovilismo. Quaderns del $C A C, 25,49-62$.

Blanch, M. (1993). Sistemas de medición de la audiencia de radio en España. Tesis doctoral. Barcelona: Universidad Autónoma de Barcelona (UAB).

Burton, L. (2008). I heard it on the radio...broadcasting in the classroom. Screen \& education, 50, 68-73.

Cantril, H. \& Allport, G.W. (1935). The psychology of radio. New Hampshire: Ayer Company.

Christenson, P.G. \& Debenedittis, P. (1985). Children's use of audio media. Communication Research, 12 (3), 327-343.

Davis, Ricardo A. (1994). Children's radio network boasts rating numbers. Advertising Age, 65.

Fryer, Michelle L. (1991). Health education through interactive radio. A child-to-child project in Bolivia. Health education \& behaviour, 18, 65-77.

Garitaonandia, C., Juaristi P. \& Oleaga, J. (1999). Qué ven y como juegan los niños españoles. Zer, Revista de estudios de comunicación, 6.

Gascón, M.C. (1991). La radio en la educación no formal. Barcelona: Ceac.

González Conde, J. (2003). Ámbitos de actuación de la radio educativa y su integración en el contexto escolar. Red Digital, 4; (reddigital.cnice.mec.es/4/firmas_nuevas/articulo4/julia_1.htm) (30-09-09).

González i Monge, F. (1989). En el dial de mi pupitre. Las ondas, herramienta educativa. Barcelona: Gustavo Gili.

Jamison, D.T. (1978). Radio for education \& development. London: Sage Publications.

Jayaprakash, Y.T. (2000). Remote audiences beyond 2000: Radio, every day life and Development in South India. International Journal of cultural studies, 3(2), .227-239. 
López Noguero, F. (2001). Los medios de comunicación en la educación social: el uso de la radio. Comunicar ,16, 141-148.

Merayo, A. (2000). Identidad, sentido y uso de la radio educativa. In Actas del III Congreso internacional Cultura y medios de comunicación. Salamanca: Universidad Pontificia de Salamana, $387-404$

Morton, J.L. (2008). I feel good! A weekly wellness radio broadcast for elementary school children. Journal of school nursing, 24, 83-87.

Muñoz, J.J. (1994). La radio educativa. Salamanca: Cervantes.

Perona, J.J. (2009). Edu-webs radiofónicas: experiencias españolas de educación en medios. Comunicar, 33, 107-114.

Petrozello, D. (1996). Children's radio: A format whose time has come?. Broadcasting \& cable, 126(42), 62-70.

Perona, J.J. \& Barbeito, M.L. (2007). Modalidades educativas de la radio en la era digital. Icono 14, 9. (www.icono14.net/revista/num9/articulos/08.pdf) (25-09-09).

Spain, P.L. et al. (1977). Radio for education \& development: case studies. World bank staff working paper, 266.

American Academic of Pediatrics (1999). Media education. Pediatrics, 104(2), 341-343.

VVAA (2007). Estudio sobre consumo televisivo y radial infantil. Perú: Compañía peruana de estudios de mercado y opinión pública (http://www.concortv.net). 
TABLE 1

Composition of the sample

\begin{tabular}{|l|r|r|}
\hline SCHOOL NAME & $\begin{array}{l}4^{\text {TH }} \text { GRADE } \\
\text { STUDENTS }\end{array}$ & $\begin{array}{l}6^{\text {TH }} \text { GRADE } \\
\text { STUDENTS }\end{array}$ \\
\hline CEIP Arc Iris (city of Barcelona) & 22 & 15 \\
\hline CEIP Dolors Montserdà-Santapau (city of Barcelona) & 39 & 37 \\
\hline CEIP Drassanes (city of Barcelona) & 21 & 16 \\
\hline CEIP Escola del Mar (city of Barcelona) & 17 & 19 \\
\hline CEIP Jacint Verdaguer (city of Castelldefels) & 21 & 15 \\
\hline TOTAL & $\mathbf{1 2 0}$ & $\mathbf{9 2}$ \\
\hline
\end{tabular}

Source: Publiradio (UAB) 
GRAPH 1

Students who explicitly mentioned the generic topics




GRAPH 2

Map of concepts related to the radio cited by the children in their essays

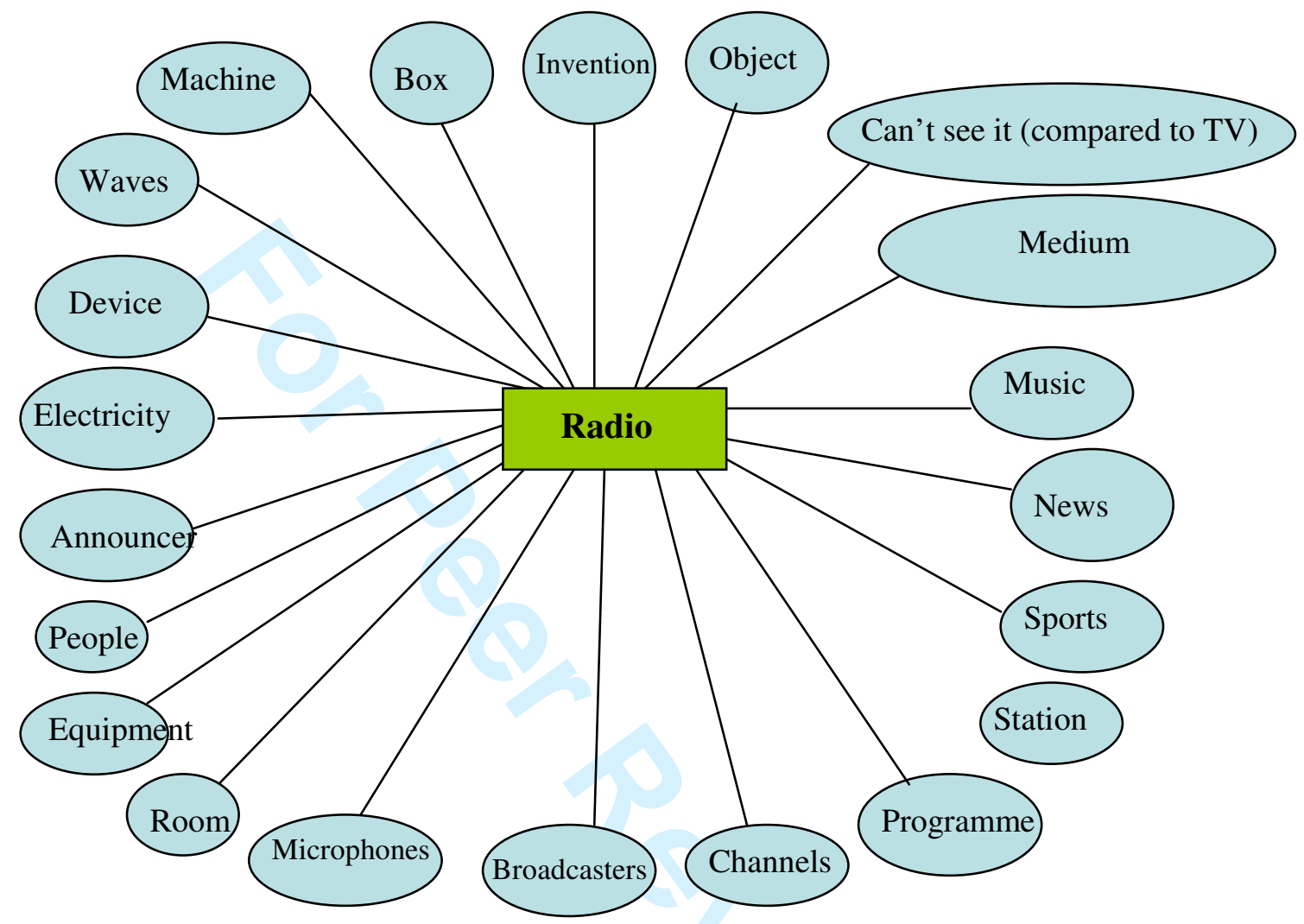

Source: Publiradio (UAB). 
TABLE 2

Frequency with which the students mentioned the main ways in which they use radio

\begin{tabular}{|c|c|}
\hline Use of the radio to listen to... & ${\text { No. of times } \text { mentioned }^{*}}^{*}$ \\
\hline Music & 19 \\
\hline Football & 18 \\
\hline News & 4 \\
\hline Weather reports & 1 \\
\hline Traffic reports &
\end{tabular}

Source: Publiradio (UAB).

* Even though these subjects are mentioned a total of 64 times, only 52 subjects offered further information on them. The presence of a higher number of mentions can be explained by the fact that some children mentioned more than one way in which they use the radio (two or more). 
GRAPH 3

Children's assessment of the radio

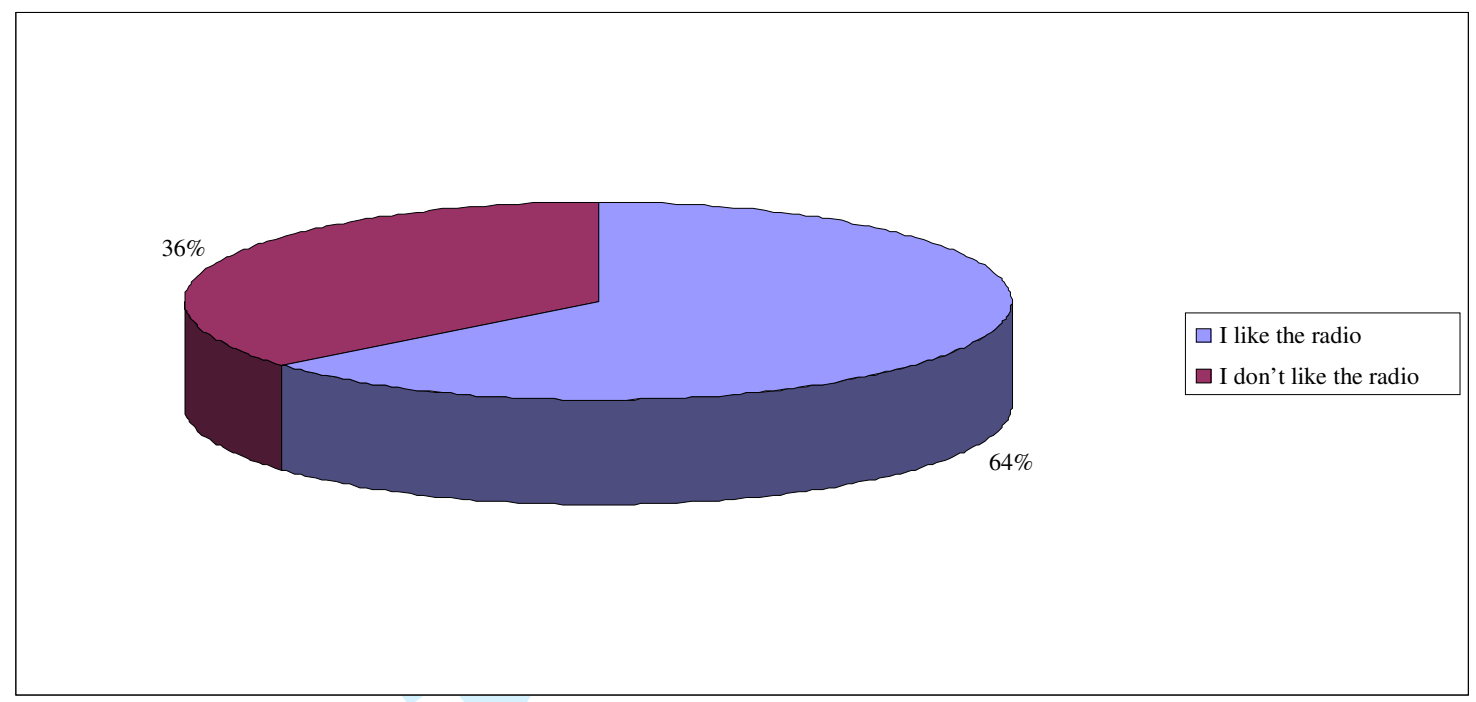

Source: Publiradio (UAB). 
GRAPH 4

Children's overall assessment of the radio

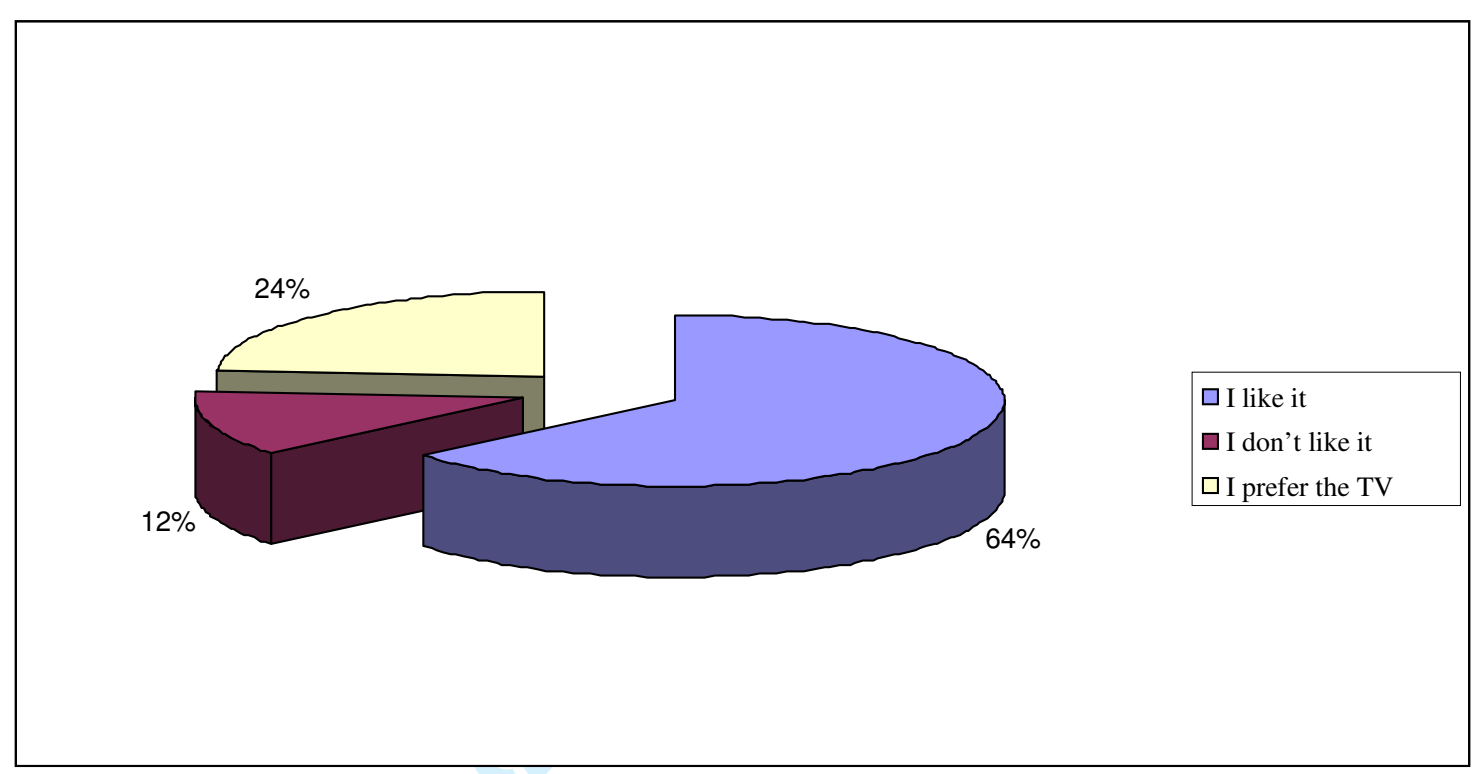

Source: Publiradio (UAB). 